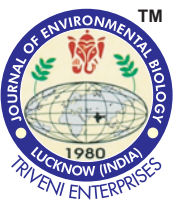

\title{
Assessment of air quality index of urban area and epidemiological investigations in Chennai
}

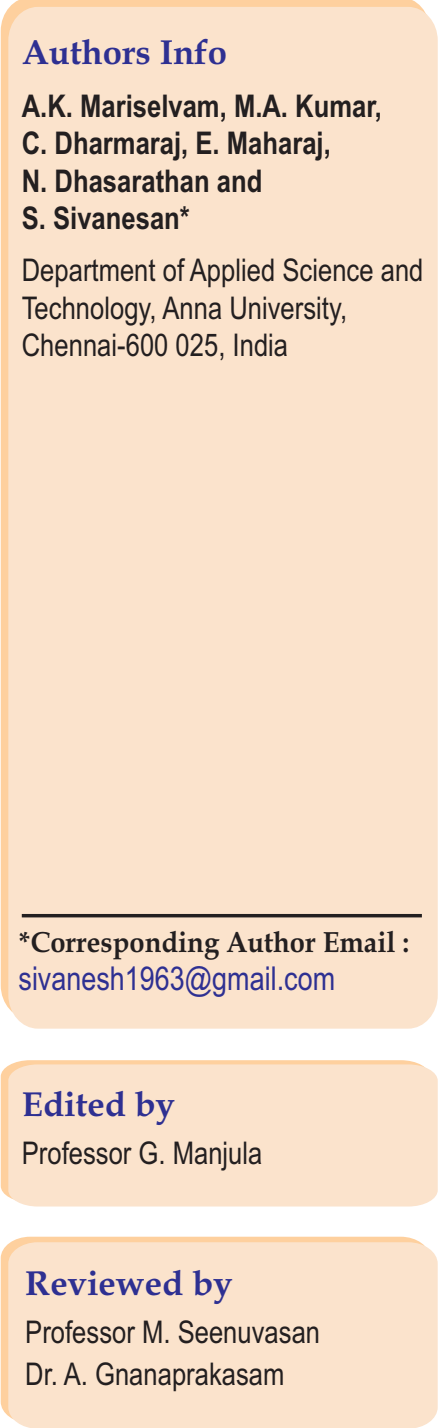

Abstract

Aim: To study air quality of Chennai city by comparing the air quality index (AQI) with the National Ambient Air Quality Standard (NAAQS) values.

Methodology : In urban area, a major straddling problem is air pollution. Analyses was conducted during Jan 2016-Dec 2017 for $\mathrm{PM}_{2.5}, \mathrm{SO}_{2}, \mathrm{NO}_{2}$ and $\mathrm{CO}$ at different seasons in Manali, Chennai. Fine particulate sampler and Lutron CO meter were used to estimate $\mathrm{PM}_{2.5}$ and COlevels.

Results: Due to different climate changes in India, higher concentration of pollution occurred during summer and monsoon season. The commercial and residential area experienced lower pollution compared with industrial areas. Case-control study showed that the result of odds ratio was significant.

Interpretation: Commercial and traffic may have significant influence on air quality in Chennai.

Key words: Air Quality Index, Air Pollutants, Epidemiological investigation, Industrial area.

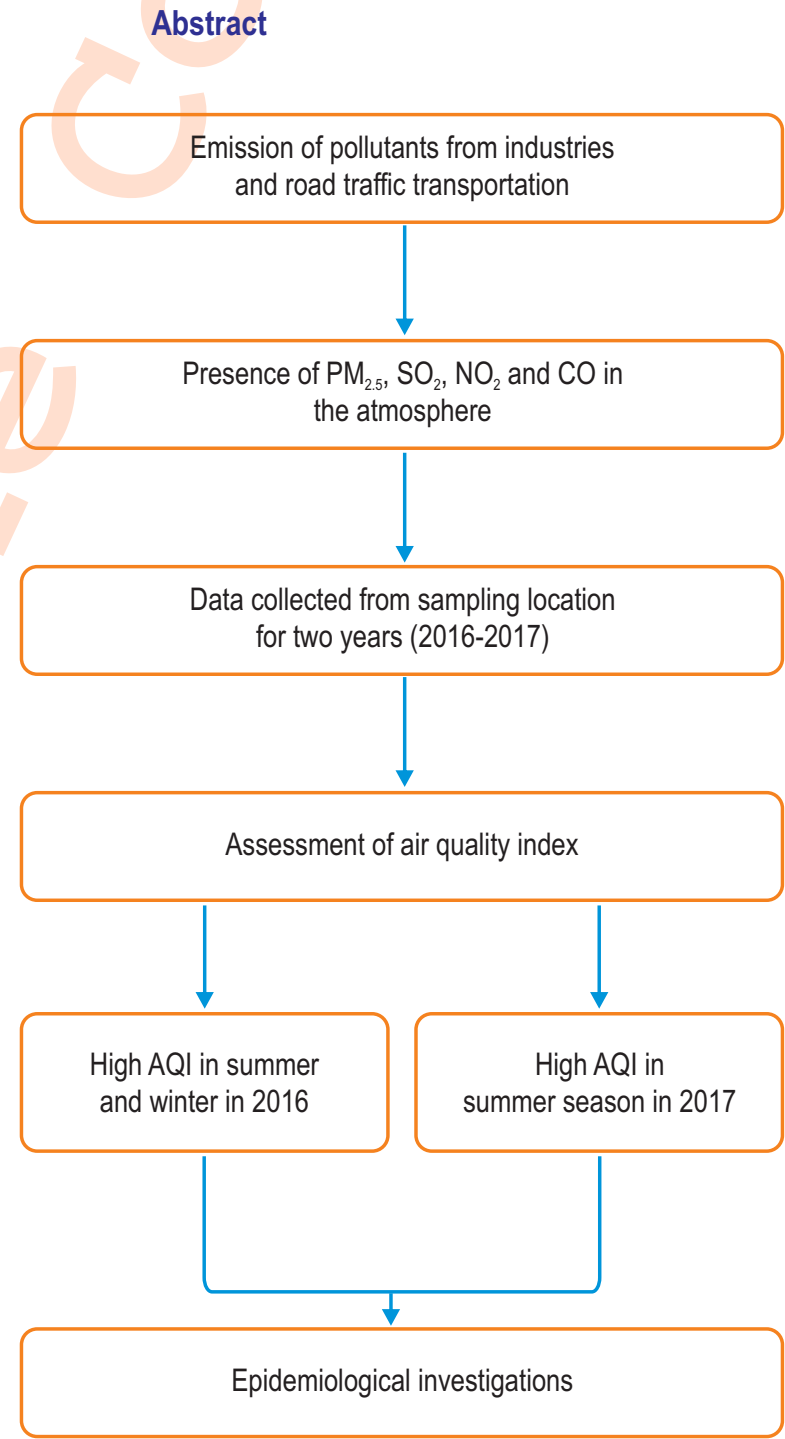

How to cite : Mariselvam, A.K., M.A. Kumar, C. Dharmaraj, E. Maharaj. N. Dhasarathan and S. Sivanesan: Assessment of air quality index of urban area and epidemiological investigations in Chennai city. J. Environ. Biol., 40,790-795 (2019). DOI : http://doi.org/10.22438/jeb/40/4(SI)/JEB_21 


\section{Introduction}

Polluted environmental condition directly affects human beings and other living organisms. Pollution free and clean environmental means absence of unwanted or foreign materials (Nikolina and Krassimira, 2014; Ministry of Environment and Forest, 1986). Air pollution is one of the dominating issues in the recent era (Dwivedi and Shashi, 2012; Lamzira Lagidze et al., 2015). In urban areas like Chennai, the industrial indoor air pollutants are another source of air pollution (Dalal et al., 2013). During festivals, bursting of firecrackers the pollutants into the atmosphere (Samavia Batool et al., 2016 and Wu N et al., 2015). There is another one source called transport source which emits severe concentration of $\mathrm{NO}_{x}, \mathrm{SO}_{2}$ to the environment (Handan Ucun Özel, 2014; Oktay et al., 2018). The burning of fuels releases these kinds of exhaust into the environment (Kiran et al., 2015; Mahla et al., 2017). Some typical industrial wood painting plants produce high volatile organic carbon (Sinha and Shivgotra, 2012; Kamakshi et al., 2019). In feeding of earthworm casts also leads to emission of air pollutants like $\mathrm{NH}_{3}, \mathrm{H}_{2} \mathrm{~S}$ (Jae-Sung Yoon and Byung-Sung, 2016; Jae-Suk Choi et al., 2014). In Chennai, level of air quality decreases rapidly due to industrial developmental activities and daily use of automobile vehicles abundantly (Ding Weina et al., 2015; Ravi etal., 2016).

Emission of unburned hydrocarbons ( $\mathrm{UBHC}$ ) and $\mathrm{NO}_{x}$ is higher while burning charcoal briquettes (Mandal et al., 2013). Pollutants like $\mathrm{SO}_{2}$ can easily dissolve in water. Leading to acid rain which affects the development of plants (Zomuanpuii et al., 2014; Ponmurugan et al., 2015). Previous studies show the various types of air pollution such as from $\mathrm{SO}_{2}, \mathrm{NO}_{2}, \mathrm{HC}, \mathrm{COx}$ and suspended particulate matter for different weather conditions (Wang et al., 2017). Due to the emission of particles like SPM, $\mathrm{NO}_{2}, \mathrm{SO}_{2}$ and $\mathrm{COx}$, it is known that illness and health afflictions are caused. ( Skromulis and Noviks, 2011). Vulnerable changes in indoor and outdoor climatic conditions often lead to health issues in children (Danesh et al., 2013). Since children are more sensitive to such affliction, they enter lungs and respiratory pathology. (Goswami et al., 2013). For adults, these air pollutants cause oxidative stress that leads to mental disorder (Durga et al., 2015; Butchiram et al., 2012).

Availability of contaminant biomass fossil fuels in villages lead to emission of hazardous pollutants in the atmosphere. It contributive to lung function abnormalities in women (Vipin et al., 2013). These excess biomass emission in fossil fuels can be removed by physical, chemical and biological method (Ojha et al., 2015). Dissolving pollutant in any coal mining industry into river affects fish population. (Mylliemngap and Ramanujam, 2011). To avoid these kinds of maladies, proper control measures and monitoring techniques should be followed in the industries as well as in vehicle emissions (Bucher, 2016; Raina Pal et al., 2014). If ASTM D6751 specification is complied, there would be a substantial reduction of $\mathrm{HC}$ and $\mathrm{CO}$ from emission form a vehicle's engine (Mahla et al., 2017). By promoting green technology, which has played a dominant role in environmental protection, the $\mathrm{CO}$ emission in a particular location gets reduced (Ding et al., 2015). Assessment of air quality index in various locations help to find out variation of polluting agents in these specific places. In a global scenario, releasing of air pollution matter shall be reduced by proper control measure (Radhapriya et al., 2012). Particulate matter refers to mixture of micro solids and micro liquid components such as nitrates, sodium salts and carbon mixing with air (Mondal et al., 2013). $\mathrm{NO}_{2}, \mathrm{SO}_{2}$ and SPM are the major air pollutants and they cause their adverse effects on human living in India (Air Quality Expert Group, 2012).

Biomonitoring of plants is used as a tool to analyse the impact of air pollution on plants (Karaer et al., 2011). The above mentioned pollutants are emitted directly from the burning of fossil fuels in industrial operation and automobile vehicles (Mohapatra and Goswami, 2012). The particulate matter particles released from metallurgical industry is also one of the root cause of air pollution (Madan and Verma, 2014). Automobile vehicle is the major source of air pollution in the urban area (Sinha and Shivgotra, 2012). It contributes $60-70 \%$ of total pollutants to environmental condition (Pollution, 2011). Air quality index score is used to assess and analyze the level of air quality in the environmental (Chaudhuri and Chowdhury, 2018). The concentration level of pollutants such as $\mathrm{SO}_{2}, \mathrm{NO}_{x}, \mathrm{HC}, \mathrm{CO}$ and suspended particulate matter may vary due to change in environmental condition ( Thambavani and Maheswari, 2013).

In the present study, an attempt was made to assess and evaluate air pollution of 2 years from of January 2016 to December 2017 during summer, winter and monsoon season in Chennai.

\section{Materials and Methods}

Study area: Chennai is one of the biggest industrial hubs in South India. Whereapproxmatly 3,500 small, medium and largescale industries operate. For this study, Manali $\left(13^{\circ} 09^{\prime} 29.7^{\prime \prime} \mathrm{N} ; 80^{\circ} 15^{\prime}\right.$ $38.8 \mathrm{n} \mathrm{E)} \mathrm{located} \mathrm{in} \mathrm{Chennai} \mathrm{was} \mathrm{selected} \mathrm{for} \mathrm{the} \mathrm{analysis} \mathrm{of} \mathrm{air}$ quality index (AQI) in various seasons. Major source of pollution in Manali are Chennai Petroleum Corporation Limited (CPCL), Ennore thermal power station, small, medium and large scale industries and heavy vehicles traffics.

The following formula was used to calculate the air quality index in a particular location (Saravanakumar et al., 2016).

$$
\begin{aligned}
& \mathrm{AQI}=1 / 4\left(\left(\mathrm{IPM}_{2.5} / \mathrm{SPM}_{2.5}\right)+(\mathrm{ICO} / \mathrm{SCO})+\left(\mathrm{ISO}_{2} / \mathrm{SSO}_{2}\right)+\left(\mathrm{INO}_{2}\right.\right. \\
& \left.\left./ \mathrm{SNO}_{2}\right)\right) \times 100
\end{aligned}
$$

In this study, nearly 731 samples of PM2.5, $\mathrm{CO}, \mathrm{SO}_{2}$, NOx were collected from Manali. It has been noted once in two days during the years 2016 and 2017. The average values of these samples were calculated for the four seasons of Chennai, 
India such as winter, summer, pre-monsoon and rainy-monsoon seasons.

Estimation of particulate matter: The respirable particulate matter (SPM) of $2.5 \mu\left(\mathrm{PM}_{25}\right)$ was measured with the help of fine particulate sampler APM 550 MINI with Teflon filter media attached for a period of one in two days. By measuring the weight of filter media before and after sampling, the concentration of $\mathrm{PM}_{2.5}$ was calculated in terms of $\mu \mathrm{g} \mathrm{m}^{-3}$.

Ambient $\mathrm{CO}$ concentration in the atmosphere was estimated by Lutron CO meter GCO-2008. CO meter is one-chip of microprocessor large scale integration circuit. The measurement was taken in an open environment by monitoring the change in reading with $\mathrm{CO}$ meter.

Modified West Gaeke method was followed to estimate $\mathrm{SO}_{2}$ in Manali. $\mathrm{SO}_{2}$ was measured by absorbing the $\mathrm{SO}_{2}$ particles from the atmosphere into a sodium tetrachloromercurate solution to make the mixture of stable dichlorosulphitomercurate. For photometrical estimation, formaldehyde was mixed with stable mixture (Saravanakumar et al., 2016). $\mathrm{NO}_{2}$ concentration in air was estimated by Jacob Hochheiser method. $\mathrm{NO}_{2}$ from the atmosphere was absorbed by sodium hydroxide solution to make a stable mixture called sodium nitrite. The photometrical estimation was used to calculate nitration produced in the mixture.

Epidemiological Investigation: By conducting a case-control study in terms of odds ratio, the effect of air pollution exposure and allergic symptoms in people of Manali. Cases and controls were determined based on defined criteria and symptoms. People with allergic symptoms (eye and nose, only eye or nose). Eligibility criteria included the people residing in Manali, Chennai for past five years presenting symptoms for the recent period (incident cases), avoiding the people those who are ailing long period of symptoms (prevalent cases).

\section{Results and Discussion}

Air quality index describes the overall atmospheric condition of the environment. Table 2 shows permissible health concern based upon AQI values. The following formula was used to calculate the air quality index in a particular location (Saravanakumar et al., 2016).

$\mathrm{AQI}=1 / 4\left(\mathrm{IPM}_{25} / \mathrm{SPM}_{2.5}+|\mathrm{CO} / \mathrm{SCO}+| \mathrm{SO}_{2} /\left(\mathrm{SSO}_{2}+\mathrm{INO}_{2} / \mathrm{SNO}_{2}\right) \times 100\right.$

In this study, the concentration level of air pollutants such as $\mathrm{PM}_{2.5}, \mathrm{CO}, \mathrm{SO}_{2}$ and $\mathrm{NO}_{2}$ in Manali location was also estimated.

Table 3 shows that in 2016 concentration of $\mathrm{CO}_{2} \mathrm{SO}_{2}$ and $\mathrm{NO}_{2}$ did not exceed the permissible limit but $\mathrm{PM}_{2.5}$ concentration level exceeded the permissible limit during summer and premonsoon season. Table 4 shows that, in $2017 \mathrm{CO}_{2}, \mathrm{SO}_{2}$ and $\mathrm{NO}_{2}$ concentration level were not exceeded in all seasonal variation with the prescribed value but $\mathrm{PM}_{2.5}$ concentration level exceeded with the prescribed value in winter season and summer season.

According to national ambient air quality standards, permissible limit of $\mathrm{CO}_{2} . \mathrm{SO}_{2}, \mathrm{NO}_{2}$ and PM 2.5 was $4000,80,80$ and 60 , respectively. Table 2 and 3 shows the statistical analysis of pollutants of study area during the year 2016 and 2017 respectively. In both years, PM 2.5 level exceeded its permissible levels as compared National AmbientAir Quality Standards.

Fig. 2 and 3 represents the calculated $A Q$ l level of pollutants in various weather conditions in 2016 and 2017. From $2^{\text {nd }} \& 3^{\text {rd }}$, it was identified that there was no dependency of pollutant in 2016 and 2017. As compared with table 2, the AQI of pollutants are falls under the moderate level of health concern in winter, summer and rainy season. In 2017, winter season only has the moderate level of health concern. The results revealed that the AQI level was not based on weather conditions. Therefore, emission sources plays important role in change of pollutants level in the study location.

The selection criteria for allergic conditions such as eye and nose irritation was that person should have been resident of Manali at least five years. Exclusion criteria defined as those who were presenting with mild symptoms and with recent duration of time and, if they residing at Manali, Chennai within past 5 years were exempted from this study. Controls were selected keeping in view that the controls were having similarities to cases as possible, except that study people were not presenting with allergic disease. Residents of Manali, Chennai, after as sorting, selected based on the inclusion and exclusion criteria were involved in the study after detailed explanation and with an informed consent. The case and control were selected $1: 2$ ratio. $A$ total number of required sample size was around 420 . The sample size we chose and analyzed is around 652. Case-control study in terms of odds ratio shown in Table 5. The odds retio measure the strength of association risk factor exposure and the disease resulting from it. A self-compiled questionnaire was prepared international standard questionnaires which will be distributed to subjects after translating in their local language to collect and assess data about their health issues and all relevant information of exposure. It is designed in such a way that it can be assessed among different age group.

Table 1: Criteria of air quality index

\begin{tabular}{ll}
\hline Air Quality Index & Levels \\
\hline 0 to 50 & Good \\
51 to 100 & Moderate \\
101 to 150 & Unhealthy for sensitive groups \\
151 to 200 & Unhealthy \\
201 and above & Hazardous \\
\hline
\end{tabular}




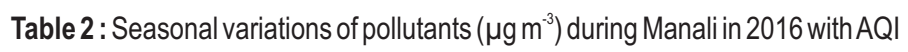

\begin{tabular}{llllll}
\hline Season & $\mathrm{PM}_{2.5}$ & $\mathrm{CO}$ & $\mathrm{SO}_{2}$ & $\mathrm{NO}_{2}$ & $\mathrm{AQI}$ \\
\hline Winter & 58.49 & 2.98 & 27.28 & 10.63 & 54.8427 \\
Summer & 95.05 & 1.51 & 26.93 & 12.06 & 61.226 \\
Monsoon rainy & 45.03 & 1.24 & 24.1 & 18.8 & 39.9188 \\
Pre-monsoon & 94.2 & 1.35 & 22.6 & 14.2 & 59.1875 \\
\hline
\end{tabular}

Table 3: Seasonal variations of pollutants $\left(\mu \mathrm{g} \mathrm{m}^{-3}\right)$ in Manali during 2017 with AQI

\begin{tabular}{llllll}
\hline Season & $\mathrm{PM}_{2.5}$ & $\mathrm{CO}$ & $\mathrm{SO}_{2}$ & $\mathrm{NO}_{2}$ & $\mathrm{AQI}$ \\
\hline Winter & $67.28 \mathrm{~s}$ & 2.39 & 30.76 & 23.08 & 59.7958 \\
Summer & 79.86 & 1.09 & 23.62 & 11.27 & 50.9906 \\
Monsoon rainy & 57.68 & 1.53 & 20.37 & 11.62 & 43.5927 \\
Pre-monsoon & 44.9 & 0.8 & 21.16 & 8.82 & 33.0771 \\
\hline
\end{tabular}

Table 4: Case-control study (odds ratio)

\begin{tabular}{lll}
\hline & Allergic disease present (Cases) & Allergic disease absent (Controls) \\
\hline Exposure present (exposed to air pollution) & 198 & 290 \\
Exposure absent (not exposed to air pollution) & 18 & 144 \\
Total & 216 & 434 \\
\hline
\end{tabular}

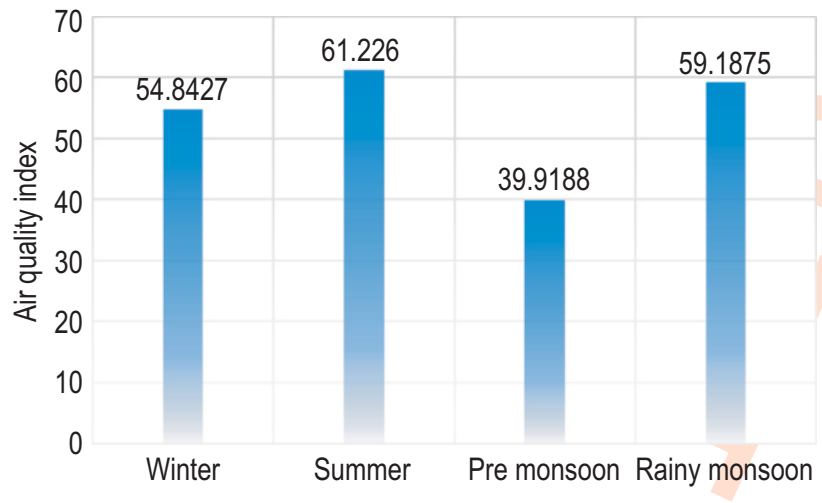

(Seasons)

Fig. 1 : Seasonal variations of air quality index of Chennai in 2016.

From the details collected, the spread sheet was made and data were interpreted manually. The routine basic statistical method is used in the above case and control study after applying values in $2^{*} 2$ table and odds ratio was estimated. Further statistical significance was derived using openepi software. From the statistical analysis, it is identified that the odds ratio of exposure to air pollution and its outcome in the form of allergic conditions as explained earlier (i.e. allergic rhinoconjunctivitis) is 5.4. In epidemiological studies, odds ratio value $>1$ suggests a positive relationship between air pollution exposure and risk of allergy.

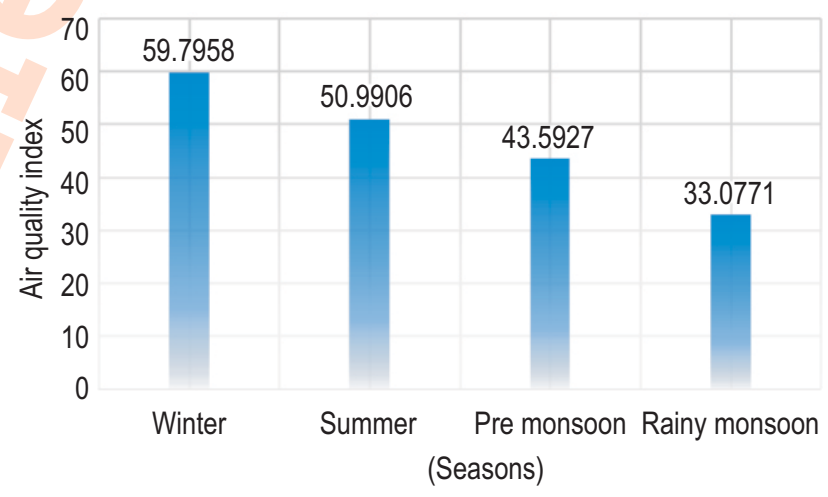

Fig. 2 : Seasonal variations of air quality index of Chennai in 2017.

The odds ratio value of 5.4 suggests that sick people have 5.4 times higher odds than controls (healthy people) having previous history of exposure to air pollution (exposure present) and it is positive association between the air pollution exposure and allergic disease (outcome), which means increased exposure causes disease and disease incidences can be significantly reduced by preventing exposure to air pollution or reducing air pollution in atmosphere, which implies impact of air pollution with health aspects of community. 


\section{References}

Air Pollution, Environmental Pollution Wageningen: Centre for Agricultural Publishing and Documentation (1970).

Ashlihan, K., F. Karaer., S. lleri, S. Sarmasik., N. Aydogan and S. Zenginay: Analysis and assessment of trace elements pollution in sediments of Lake Uluabat, Turkey. J. Environ. Biol., 33, 961-968 (2012).

Batool, S., S.A. Rashid, M.J. Moah, M. Sarfraz and M.A. Ashraf: Geographical distribution of persistent organic pollutants in the environment:Areview. J. Environ. Biol., 37, 1125-1134 (2016).

Bihari, V., S.M. Iqbal, L.P. Srivastava, C. Kesavachandran and M.J. Siddique: Lung function impairment in women exposed to biomass fuels during cooking compared to cleaner fuels in Uttar Pradesh, India. J. Environ. Biol., 34, 971-974(2013).

Butchiram, M.S., M. Kumar and K.S. Tilak: Studies on the histopathological changes in selected tissues of fish Labeo rohita exposed to phenol. J. Environ. Biol., 34, 247-251 (2013).

Chaudhuri, S. and A.R. Chowdhury: Air quality index assessment prelude to mitigate environmental hazards. Nat. Hazards., 91, $1-17(2018)$.

Choi, J.S., Y.M. Ha., B.B. Lee., H.E. Moon, K.K. Cho and I.S. Choi: Seasonal variation of antibacterial activities in the green alga Ulva pertusa Kjellman. J. Environ. Biol., 35, 341-344 (2014).

Dalal, P., D. Chaudhry and V. Shukla: Analysis of heavy metals concentration in ambient air and in human population of Rohtak, India. J. Environ. Biol., 34, 945-949 (2013).

Danesh, N., E.T. Puttaiah and B.E. Basavarajappa: Studies on diversity of lichen, pyxine cocoes to air pollution in Bhadravathi town, Karnataka, India. J. Environ. Biol., 34, 579-584 (2013).

Ding, W., B. Han, X. Zhao and M. Mazzanti: How does green technology influence $\mathrm{CO}_{2}$ emission in China?--An empirical research based on provincial data of China. J. Environ. Biol., 36, 745-753(2015).

Durga, M., S. Bharathi, P.B. Murthy and T. Devasena: Characterization and phytotoxicity studies of suspended particulate matter (SPM) in Chennai urban area. J. Environ. Biol.,36, 583-589 (2015).

Ding, W., H. Botang, Z. Xin and M. Mazzanti: How does green technology influence $\mathrm{CO}$ emission in China? -An empirical research based on provincial data of China. J. Environ. Biol., 36, 745-753 (2015).

Dwivedi, A.K. and Shashi: Ambient air sulphur dioxide and sulphate accumulation in deciduous and evergreen plants. J. Environ. Biol., 33, 1-3 (2012).

Goswami, S., B.K. Swain, H.P. Mohapatra and K.K. Bal: A preliminary assessment of noise level during Deepawali festival in Balasore, India. J. Environ. Biol., 34, 981-984 (2013).

Handan, U.Ö.: The effects of dusts of bartin cement factory on Taurus Cedar (Cedru libani A Rich.) seeds' germination. J. Environ. Biol., 37, 1331-1334 (2016).

Jae, S.Y. and B.S. Park: Effect of fermented earthworm cast on egg production and egg quality as well as removal of odor in feces from egg laying hens. J. Environ. Biol., 37, 591-596 (2016).

Kiran, K.R., M.V. Ravi, B. Dhanya, B.S. Janagoudar, M.R. Umesh and K. Narayanarao: Do emissions from thermal power plants affect crop productivity? A study from the vicinity of Bellary Thermal Power Station, Karnataka, India. J. Environ. Biol., 37, 949-954 (2016).

Mahla, S.K., A. Dhir, V. Singla and P. Rosha: Investigations on environmental emissions characteristics of $\mathrm{Cl}$ engine fuelled with castor biodiesel blends.J. Environ. Biol., 39, 353-357(2018).

Mandal, S., A. Kumar, R.K. Singh, S.V. Ngachan and K. Kundu: Drying, burning and emission characteristics of beehive charcoal briquettes: An alternative household fuel of Eastern Himalayan Region. J. Environ. Biol., 35, 543-548(2014).

Ministry of Environment and Forest. The Indian Environment Protection Act,1986 INDIAN Environ. ACT (1986).

Mohapatra, H. and S. Goswami: Impact of coal mining on soil characteristics around lb river coalfield, Orissa, India. J. Environ. Biol., 33, 751-756 (2012).

Mondal, N.K., R. Bhaumik, C.R. Das, P. Aditya, J.K. Datta, A. Banerjee and K. Das: Assessment of indoor pollutants generated from bio and synthetic fuels in selected villages of Burdwan, West Bengal. J. Environ. Biol., 34, 963-966 (2013).

Mylliemngap, B.K. and S.N. Ramanujam: Morphological changes in the gills of Heteropneustes fossilis (Bloch) exposed to coal mining effluent water. J. Environ. Biol., 33, 735-739 (2012).

Ojha, S.K., S. Mishra, S. Kumar, S.S. Mohanty, B. Sarkar, M. Singh and G.R. Chaudhury: Performance evaluation of vinasse treatment plant integrated with physico-chemical methods. J. Environ. Biol., 36, 1269-1275 (2015).

Oktay, M.K., B. Sahin and H. Güneş:Characterization of native Bacillus thuringiensis strains for cytotoxicity against human cancer cell lines. J. Environ. Biol., 39, 958-965 (2018).

Ponnusamy, P., G. Ayyappadasan, R.S. Verma and S. Nayaka: Survey, distribution pattern and elemental composition of lichens in Yercaud hills of Eastern Ghats in southern India. J. Environ. Biol., 37, 407-412 (2016).

Radhapriya, P., A.N Gopalakrishnan, P. Malini A. and Ramachandran: Assessment of air pollution tolerance levels of selected plants around cement industry, Coimbatore, India. J. Environ. Biol., 33, 635-641 (2012).

Sangeeta, M. and P. Verma: Assessment of air pollution tolerance index of some trees in Haidwar City, Uttarakhand. J. Environ. Biol., 36 645-648 (2015).

Sarala, T.D. and J. Maheswari: Source apportionment of particulate air pollution and percentage contribution of $\mathrm{PM}_{10}$ and $\mathrm{PM}_{2.5}$ using chemical mass balance (CMB) method. Chem Sci Trans., 2, 614$620(2013)$

Ravi, V., S.J. More, R. Saravanan, G. Byju, M. Nedunchezhiyan, A.A. Devi and K.P. Nair: Potential increase in photosynthetic response of taro (Colocasia esculenta L.) to photon flux density and elevated $\mathrm{CO}_{2}$. J. Environ. Biol., 38, 67-74 (2016).

Saravanakumar, R., S. Sivalingam and S. Elangovan: Assessment of air quality index of Coimbatore city in Tamil Nadu. Ind. J. Sci. Technol., 9, 1-5 (2016).

Sinha, S.N and V.K. Shivgotra: Environmental monitoring of adulterated gasoline with kerosene and their assessment at exhaust level. J. Environ. Biol., 33, 729-734 (2012).

Skromulis, A. and N. Gotfrids: Atmospheric light air ion concentrations and related meteorologic factors in Rezekne city, Latvia. J. Environ. Biol., 33, 455-462 (2012).

Slavomir, B.: Environmental performance as one of the indicators of sustainable development in Asia. J. Environ. Biol., 38, 67-74 (2017).

Rita, Z., G. Guruswami and S.K Nachimuthu: A three year study on distribution and ecology of Anophelines in Thenzawl, Mizoram, India. J. Env. Biol., 35, 369-376 (2014).

Raina, P., Mahima, A. Gupta and A. Tripathi:Assessment of heavy metals in suspended particulate matter in Moradabad, India. J. Environ. Biol., 35, 357-361 (2014). 
Kamakshi, N., D. Sagar, V. Jayalakshmi and S. Chander: Weather prediction model for beet armyworm (Spodoptera exigua Hubner) in chickpea. J. Environ. Biol., 40, 84-88 (2019).

Tzvetkova, N. and K. Petkova: Bioaccumulation of heavy metals by the leaves of Robinia pseudoacacia as a bioindicator tree in industrial zones. J. Environ. Biol., 36, 59-63 (2015).

U.S. Environmental Protection Agency, 2010. National Ambient Air Quality Standards (NAAQS).

Wang, M., C. Gui, H. Li, H. Wang and D. Song: Study on mercury in airborne particulates from different functional areas of Jiaozuo City, China. J. Environ. Biol., 39, 481-485 (2017).

Wu, N., H. Qian, Y. Tan and Y. Wang: Effect of nitrogen addition on carbon and nitrogen stable isotopes in temperate forest litter and soil. $\mathrm{J}$. Environ. Biol., 39, 1036-1040 (2018).

Lagidze, L., L. Matchavariani, N. Tsivtsivadze, N. Khidasheli, N. Paichadze, N. Motsonelidze and M. Vakhtangishvili: Medical aspects of atmosphere pollution in Tbilisi, Georgia. J. Environ. Biol., 36, 101-106 (2015). 